\title{
Strategic Exploration on the Popularization of Sexual Science Knowledge among Normal Students under the Opening-Up Background
}

\author{
Keli Liao, Quanming Liao, Tao Hu \\ School of Psychology, Chengdu Normal University, Chengdu, China \\ Email: keli85577273@126.com
}

How to cite this paper: Liao, K.L., Liao, Q.M. and Hu, T. (2019) Strategic Exploration on the Popularization of Sexual Science Knowledge among Normal Students under the Opening-Up Background. Open Journal of Applied Sciences, 9, 851-856. https://doi.org/10.4236/ojapps.2019.912068

Received: November 1, 2019

Accepted: December 9, 2019

Published: December 12, 2019

Copyright () 2019 by author(s) and Scientific Research Publishing Inc. This work is licensed under the Creative Commons Attribution International License (CC BY 4.0).

http://creativecommons.org/licenses/by/4.0/

\begin{abstract}
Through the development of interdisciplinary public elective courses of sexuality in the whole school, systematic education of sexology knowledge is carried out for normal students, so that normal students can understand the sexual knowledge of male and female students, such as reproductive structure, function, reproductive health care, sex and sexual psychology, so as to reduce the premarital sexual behavior of normal students, avoid premarital pregnancy, reduce the incidence of reproductive tract infection and sexually transmitted diseases, improve the ability of self-protection of normal students, cultivate good sexual psychology of normal students, and promote the physical and mental health of normal students.
\end{abstract}

\section{Keywords}

The Opening-Up Background, Normal School Students, Sexual Science Knowledge, Strategy

\section{Introduction}

After the reform and opening up, with the impact of western culture and the rapid development of network information technology, college students are more and more open and casual about sex, but the corresponding education has not kept up with it. Their low level of knowledge about sexual science, lack of sexual morality and fragile sexual psychology lead to the increasing incidence of premarital sexual behavior, unmarried pregnancies, sexually transmitted diseases and sexual crimes among college students, and show a trend of younger age. Normal school students undertake the arduous task of training the next generation, so their physical and mental health directly affects the future of the mo- 
therland.

With the growing maturity of physiological development, normal students' desire for heterosexual communication is becoming stronger and stronger, accompanied by varying degrees of sexual impulses and sexual needs. Since our country always turns pale at the mention of sex, believing that sex is dirty, obscene, and unworkable, parents either avoid or rebuke the questions about sex raised by students. Teachers either speak just a little bit about sexual knowledge or do not speak at all. Students can only obtain knowledge about sex from the Internet, pornographic magazines, film and television works, etc. Under such an opening-up background, normal university students have a low level of knowledge of sex science, lack of sexual moral awareness, are fragile in sexual psychology, and still have many problems in sexual behavior. Peng Mingfang's research on domestic scholars in the past decade found that sex education for college students has not yet been popularized and has obvious marginalization characteristics [1]. In the 1960s, sex education has become a compulsory course for primary and secondary school students in many countries, which is not only the change of people's sexual cognition, but also the need of human physiologi$\mathrm{cal}$ and psychological development. But in our country, there are some obstacles in the research of sexual science and the popularization of sexual knowledge [2]. Due to the lack of systematic knowledge of sexual and reproductive health, most normal students lack a correct understanding of the serious consequences caused by unexpected pregnancy, unsafe abortion, reproductive tract infection, sexually transmitted diseases infection and transmission, etc. Moreover, they do not have the ability to negotiate, communicate, refuse and protect themselves when having sex, lack correct, timely and effective contraceptive measures or insist on using contraceptive measures, and some normal students even have dangerous sexual behaviors, such as commercial sex, multiple sexual partners, etc., which make them face increased risks of unwanted pregnancy, reproductive tract infection, induced abortion, sexual violence and sexually transmitted diseases, seriously affecting the physical and mental health of normal students.

Many colleges and universities also try to conduct sex education through one or two lectures, but the results are poor. The overall feeling of students towards sex education in schools is that only $16 \%$ of them have "gained greatly" and "gained a lot" [3]. Many scholars have put forward some educational countermeasures for the current situation of College Students' lack of sexual science knowledge, such as: Zheng Shengde's proposal to change educators' ideas, strengthen the construction of teachers, build a scientific curriculum system, set up scientific content of popularization of sexual science knowledge, and make full use of network media, etc. [4]. Cao Xiaomei put forward the comprehensive nature of sex education: the organic combination of sexual physiology knowledge, sexual psychology knowledge and sexual morality, and also pay attention to the long-term and high level of sex education [5]. Wu Yang proposed to strengthen teacher training and scientific research, improve teaching methods and improve the three-dimensional education model of school, family and 
community interaction [6]. Most of these educational countermeasures are proposed from a macro perspective, and there seems to be no empirical test.

In order to observe the situation of normal students' acquisition of sexual science knowledge, this study aims to popularize sexual science knowledge among normal students by offering a school-wide interdisciplinary elective course in Chengdu Normal University.

\section{Research Object and Method}

The research objects were determined through online free course selection in Chengdu normal university, with a total of 56 students. See Table 1 for students' specific information.

The public elective course lasts 16 hours. The teaching content includes five topics: sexual physiology, sexual psychology, sexual morality, sexual behavior and sexually transmitted diseases. In order to get to know the students' mastery of sexual knowledge, a simple test was made before teaching. After completing the 16-hour teaching task, a test was conducted to verify the effect of students' acquisition of sexual science knowledge through teaching activities.

\section{Research Results and Analysis}

\subsection{Mastery of Sexual Science Knowledge by Normal Students before Teaching}

About $80 \%$ of normal school students can correctly answer basic knowledge about sex, such as menarche and menstruation, common complications of induced abortion, common contraceptive methods used by unmarried women, transmission routes of AIDS and high-risk behaviors. In the answers to open questions, for example, "What else do you want to know about sex? What kind of help do you want?" most normal students are mainly interested in sexual behavior and sexual safety measures, such as: what kind of sexual behavior is correct?

Table 1. Students' major, grade, gender and educational background.

\begin{tabular}{|c|c|c|c|c|c|c|c|c|c|c|c|c|c|}
\hline Major & & 芯 & 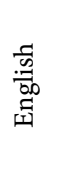 & 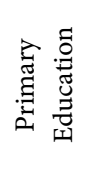 & 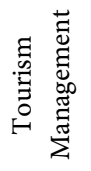 & 号 & 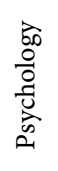 & 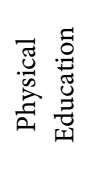 & 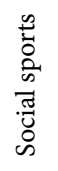 & 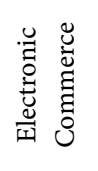 & 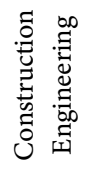 & 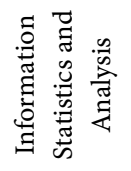 & 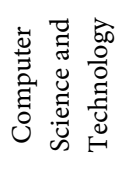 \\
\hline \multirow{3}{*}{ Grade } & Sophomores & & & 10 & 8 & & 3 & 1 & & & & 1 & 4 \\
\hline & Junior & 3 & 9 & & & 1 & & & 2 & 11 & 1 & & 1 \\
\hline & Senior & & & & 1 & & & & & & & & \\
\hline \multirow{2}{*}{ Gender } & Boy & & 2 & 5 & 3 & & & 1 & 1 & 3 & 1 & & 3 \\
\hline & Girl & 3 & 7 & 5 & 6 & 1 & 3 & & 1 & 8 & & 1 & 2 \\
\hline Educational & Undergraduate & 3 & 8 & & & & 3 & & 2 & & & & 5 \\
\hline Background & Junior College & & & 10 & 10 & 1 & & 1 & & 11 & 1 & 1 & \\
\hline Total & & 3 & 8 & 10 & 10 & 1 & 3 & 1 & 2 & 11 & 1 & 1 & 5 \\
\hline
\end{tabular}


How to use condoms correctly? What are the hazards of contraceptives? How to achieve sexual safety? What is the difference between male and female students' sexual psychology? How to reduce the harm caused by premarital sex? What should we do in case of accidental pregnancy? What should we do after suffering from venereal diseases? How should women protect themselves in the face of sexual behavior? Is sexual exclusion a mental illness? And the like.

\subsection{Mastery of Sexual Science Knowledge by Normal Students after Teaching}

After the end of the elective course, normal school students were examined from five aspects: sexual physiology, sexual psychology, sexual behavior, sexual morality and sexually transmitted diseases. From the results of the examination, it can be seen that:

Firstly, most of the normal school students have a comprehensive and correct understanding of the structure and function of male and female reproductive system, especially the periodic changes of female ovaries, the formation of menstrual cycle, the process of conception and the related knowledge of reproductive health of men and women. For example: Know that the so-called safe-period contraception is not actually safe.

Secondly, most normal school students have a preliminary understanding of the biological basis, psychological factors and environmental factors of sexual desire, know the main ways and methods to alleviate sexual desire; know the common sexual behavior of college students and the correct attitude to it.

Thirdly, normal school students have a better understanding of the transmission routes, main symptoms and preventive measures of STDs, especially the symptoms and preventive measures of other common STDs besides AIDS. Before teaching, the vast majority of normal school students only know that AIDS is a sexually transmitted disease, and little is known about other sexually transmitted diseases. More than half of normal school students have not even heard of sexually transmitted diseases such as gonorrhea, condyloma acuminatum, genital herpes and non-gonococcal urethritis, let alone how to identify and prevent such sexually transmitted diseases.

Fourth, students have a certain understanding of the sexual psychological characteristics of college students and the sexual morality that male and female college students should adhere to. Most female normal students have certain self-protection skills.

Through the comparison of students' sex science knowledge education before and after the public elective course, it can be seen that students' knowledge of sexual science has increased significantly in both breadth and depth.

\subsection{Analysis of Research Results}

From the survey results before the teaching of normal students, it can be seen that the demand for sexual knowledge of normal students is no longer a simple knowledge of sexual physiology. The occurrence of sexual behavior in normal 
school students is very common, and it is a normal phenomenon. They are more concerned about how to choose a correct and safe sexual behavior, more concerned about the correct remedial measures after sexual behavior and the different psychological characteristics of men and women.

From the examination results of normal students after teaching, we can see that systematic, comprehensive and detailed sex science education can achieve better results and help normal students master safe and effective contraceptive measures, can help normal school students identify several common sexually transmitted diseases and familiarize themselves with their preventive measures, help normal school students understand the sexual morality that they should adhere to when they get along with the opposite sex, and help normal school girls master some self-protection skills, etc.

\subsection{Deficiencies of This Study}

The public elective course in this research institute is the traditional way of teaching (in the classroom). However, due to the emergence of online courses such as $\mathrm{Mu}$ class, students can study directly on the computer without the limitation of time and place, resulting in the traditional teaching method in the classroom is not liked by students. As a result, the number of students selected for this course is too small, only 56, lacking enough persuasion.

In the future, we will consider conducting online teaching to expand the popularization of sex education, and further observe the effect of this approach on the popularization of sexual science knowledge. It also hopes to provide reference for future scholars in conducting sex education research.

\section{Conclusion}

It is effective to carry out systematic sex science knowledge education for normal students in universities, which is worthy of large-scale recommendation, and even can be carried out as a public course for college students.

\section{Foundation Project}

Sichuan Key Research Base of Philosophy and Social Sciences, Sichuan Research Center of Sexual Sociology and Sexual Education: Strategic Research on the Popularization of Sexual Science Knowledge for Normal Students under the Open Background (SXJYB1709).

\section{Conflicts of Interest}

The authors declare no conflicts of interest regarding the publication of this paper.

\section{References}

[1] Peng, M.F., et al. (2014) A Summary of the Research on Sex Education of College Students in China in the Past Decade. Journal of Sichuan University of Science \& 
Engineering (Social Sciences Edition), 2014, No. 4.

[2] Wang, H.X. (2013) Current Situation and Countermeasures of Sexual Health Education for Medical College Students. Educational Science Research, No. 7, 165-166.

[3] Luo, G., Luo, L.S. and Huang, X.G. (2014) Current Situation of College Sexual Education and Potential Solutions. The Chinese Journal of Human Sexuality, 23, 98.

[4] Zheng, S.D., Zhou, L.H. and Chen, F.J. (2012) Sex Knowledge Education in Medical Universities: An Example from Medical Universities in Anhui. The Chinese Journal of Human Sexuality, 21, 69-70.

[5] Cao, X.M. (2014) Current Situation and Countermeasure of Sexual Knowledge Education for College Students. Learning Weekly, 34, 236.

[6] Wu, Y. and Yin, T.F. (2006) Current Situation of College Students' Sexual Knowledge and Behavior and Sexual Education Strategies. Chinese Journal of School Health, 27, 715 . 